\section{Planting Systems Influence Growth Dynamics and Quality of Fresh Market Spinach}

\author{
Daniel I. Leskovar ${ }^{1}$ and Larry A. Stein \\ Texas Agricultural Experiment Station, Texas Agricultural Extension Service, \\ Department of Horticultural Sciences, Texas A\&M University, 1619 Garner \\ Field Rd., Uvalde, TX 78801 \\ Frank J. Dainello \\ Texas Agricultural Extension Service, Department of Horticultural Sciences, \\ Texas A\&M University, College Station, TX 77843
}

Additional index words. Spinacea oleracea, mulch, plant density, root growth, shoot growth, within-row spacing

\begin{abstract}
The objective of this work was to determine the effect of within-row plant spacing and mulching on growth, quality, and yield of an experimental semi-savoy spinach (Spinacea oleracea L.) genotype 'Ark-310' to produce a high quality fresh market product. Within-row spacings were 15 and $25 \mathrm{~cm}$, and mulching treatments were bare-soil and black polyethylene mulch. Plants were destructively sampled weekly (1995-96) or biweekly (1997-98) for leaf area (LA), leaf number, leaf dry weight (LDW) and root dry weight (RDW) measurements. Plants grown on plastic mulch at $25-\mathrm{cm}$ spacing had greater LA, LDW, and RDW than when grown at $15-\mathrm{cm}$ spacing on mulch or bare-soil. Leaf number and specific leaf area (LA/LDW) were less affected by either spacing or mulching. The amount of soil on harvested leaves was lower on plants grown on plastic mulch in both years. In one year, total yields $\left(\mathrm{MT} / \mathrm{ha}^{-1}\right)$ were $42 \%$ higher at $15-\mathrm{cm}$ than at $25-\mathrm{cm}$ plant spacing, while mulch increased yields by $20 \%$, independently of plant spacing. These effects were not evident in the year with higher rainfall (1997-98).
\end{abstract}

Spinach is a popular salad vegetable providing significant amounts of vitamin A, vitamin C, calcium and iron. In southwest Texas, $\approx 2500$ ha of fresh market spinach are planted in the fall, accounting for $10 \%$ of the total U.S. production. However, fresh market spinach production has declined since 1987 (J. Peña, personal communication). Low market prices, use of disease-susceptible cultivars, low yields and lack of maintenance of quality, such as cleanliness, color, and texture, are factors contributing to this decline. Most fresh-market spinach grown in Texas is a savoy leaf type resulting from an increase in growth of parenchyma tissues between leaf veins. It is handharvested by cutting leaves just above the growing point and field-packing into wooden bushel baskets. This practice is ineffective in maintaining a high quality final product able

Received for publication 28 Dec. 1999. Accepted for publication 10 Apr. 2000. We thank R.W. Sprague, J.C. Ward, and K.G. White for assistance in the field; T.E. Morelock, Univ. of Arkansas, for providing the experimental spinach genotype; and $\mathrm{J}$. Parsons and Peterson Brothers Nursery for providing transplants. Mention of a trademark, proprietary product or vendor does not constitute a guarantee or warranty of the product, nor does it imply approval or disapproval to the exclusion of other products or vendors that may also be suitable. The cost of publishing this paper was defrayed in part by the payment of page charges. Under postal regulations, this paper therefore must be hereby marked advertisement solely to indicate this fact.

1'E-mail address: d-leskovar@tamu.edu to compete with either bunched root-cut or bagged baby leaf spinach and/or other loosehead salad vegetables such as lettuce. Therefore, there is a need to develop spinach production systems for improved yield while maintaining preharvest quality. This parallels the advent of new, fresh market genotypes being developed by the Univ. of Arkansas and characterized by slow growth, dark green color, superior pack-out appearance, and partial resistance to fungal diseases such as white rust (Albugo occidentalis) and blue mold (Peronospera farinosa f.sp. spinaciae).

Plant population and mulching have pronounced effects on growth and yield of many vegetable crops. However, few studies on plant spacings have been conducted in spinach. Bradley et al. (1975) and Osborne (1966) reported higher yield of canned spinach at lower bed or in-row spacing. Advantages of using plastic mulch as a component of intensive production systems has been documented with cucurbits and solanaceous crops but not with leafy vegetables (Lamont, 1993). The aim of this study was to determine if plant namics, product cleanliness, quality, and yield of an experimental fresh market spinach genotype established by transplanting.

\section{Materials and Methods}

An experimental semi-savoy spinach genotype 'Ark-310', developed by the Univ. of Arkansas for superior leaf quality characdensity and mulching affect plant growth dy- teristics, was used in this study. Transplants were grown by Peterson Brothers Nursery, San Antonio, Texas. Seeds were placed in 13$\mathrm{cm}^{3}$ peat pots containing $33 \%$ peat, $33 \%$ vermiculite, and $33 \%$ washed sand media on 4 Sept. 1995 and 24 Sept. 1997. Transplants were watered and fertilized according to Peterson's standard nursery practices. They were hand-transplanted on a Uvalde silty clay loam (fine-silty, mixed, hyperthermic Aridic Calciustoll) soil at the Texas Agricultural Experiment Station (TAES), Uvalde on 13 Nov. 1995 and 3 Dec. 1997. Plants were grown on 8-m raised (15-cm-high) beds with $1.93 \mathrm{~m}$ between beds, with four rows spaced $25 \mathrm{~cm}$ apart in the bed. In-row spacing treatments were 15 and $25 \mathrm{~cm}$, representing a plant population of 138,169 and 82,901 plants/ha, respectively. Mulching treatments were baresoil vs. black polyethylene mulch.

Plant water requirements were supplied using a drip irrigation system. Two drip tubes per bed were positioned at the soil surface in 1995 and at 10-cm depth in 1997. A Typhoon ultra light tape of $0.25-\mathrm{mm}$ wall thickness (Netafim Irrigation, Austin, Texas), with emitters spaced every $30 \mathrm{~cm}$, delivered a flow rate of $340 \mathrm{~L} \cdot \mathrm{h}^{-1}$ per $100 \mathrm{~m}$ of bed at $55 \mathrm{kPa}$. Total rainfall during the study was 101 and $141 \mathrm{~mm}$ in 1995-96 and 1997-98, respectively. An additional 17 and $95 \mathrm{~mm}$ of water were supplied between 8 Dec. and 25 Jan. 1996, and between 3 Dec. and 2 Mar. 1998, respectively. Fertilizer was applied through the drip system $\left(50 \mathrm{~N}-40 \mathrm{P}-130 \mathrm{~K} \mathrm{~kg} \cdot \mathrm{ha}^{-1}\right)$ using potassium nitrate, phosphoric acid, and urea. Metalaxyl fungicide, [(2, 6-dimethylphenyl)-N-(methoxyacetyl) alanine methyl ester] (25.1\% a.i.), at $1.04 \mathrm{~L} \cdot \mathrm{ha}^{-1}$ was applied preplant through the drip system. Weed control between beds and pest control were performed as needed.

Three plants per replication were destructively sampled ten times at weekly intervals from 13 Nov. until 16 Jan. 1996 and eight times at bi-weekly intervals from 4 Dec. until 17 Mar. 1998 (the $1^{\text {st }}$ through the $8^{\text {th }}$ sampling week). Roots were excavated with a shovel in an area $15 \times 15 \mathrm{~cm}$, with the plant in the center of the square, to a depth of $30 \mathrm{~cm}$. Soil-root samples were gently shaken to remove the adhering soil and washed by soaking in water using a $20-\mathrm{L}$ container. Leaves $>2 \mathrm{~cm}$ long were counted and leaf area was determined using a digital image analysis system (DIAS; Decagon Devices, Pullman, Wash.). Plants were oven-dried at $65^{\circ} \mathrm{C}$ for $5 \mathrm{~d}$ and leaf and root dry weights were determined.

Spinach plants were harvested from a 7.6- $\mathrm{m}^{2}$ section per plot on $25 \mathrm{Jan} .1996$ and 18 Mar. 1998, cut at the hypocotyl base and weighed. Ten random plants per replication were selected to collect soil attached to individual plants. They were washed on filter paper, and the amount of soil was collected, dried and weighed.

A randomized complete-block design with four replications of four rows $8 \mathrm{~m}$ long was used. Leaf number, leaf area (LA), leaf dry weight (LDW), root dry weight (RDW), specific leaf area (SLA $=$ LA/LDW), yield, and the amount of soil/plant were subjected to 
analysis of variance and means were separated by LSD at $P \leq 0.05$ (SAS Institute, Cary, N.C.).

\section{Results and Discussion}

Growth components. In the 1995-96 experiment, LA of transplants grown on plastic mulch was greater than that of those on bare soil $21 \mathrm{~d}$ after transplanting (DAT), reaching a plateau after 49 DAT (Fig. 1A). This increase was greater at the $25-\mathrm{cm}$ than at the $15-\mathrm{cm}$ spacing. Black plastic mulch increases soil temperature, surface temperature, and maintains higher soil moisture by suppressing soil water evaporation in comparison with bare soil (Ham et al., 1993). Spacing did not affect LA on plants grown on bare soil (Fig. 1A). In
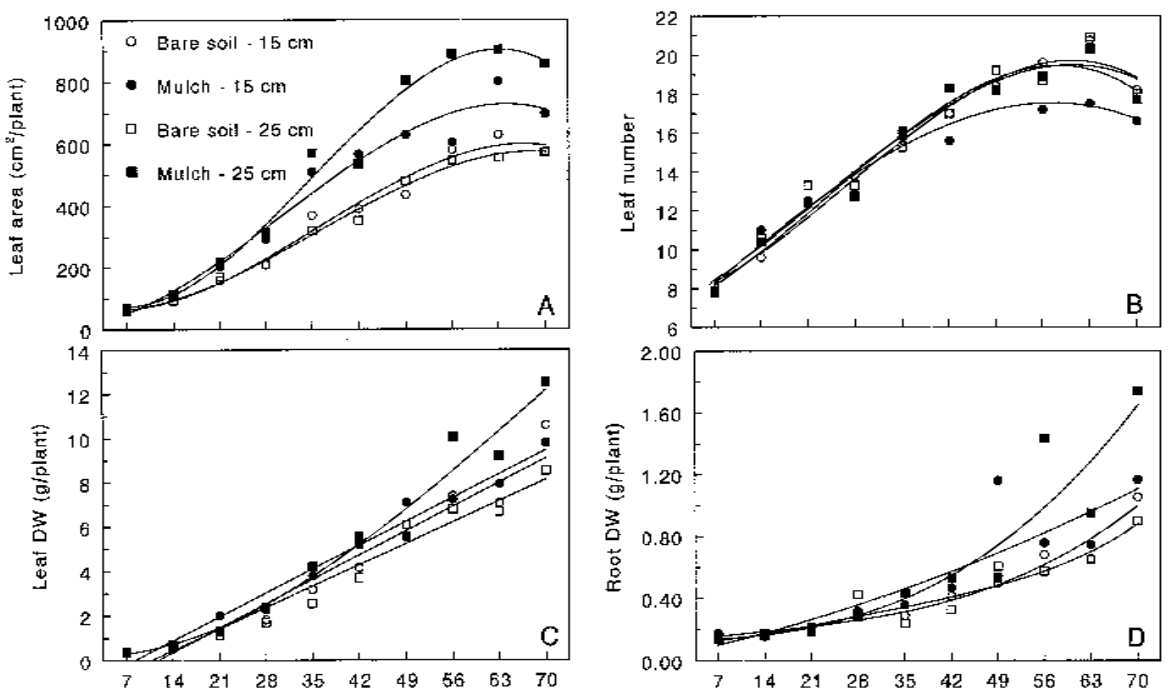

Time ( $d$ after transplanting)

Fig. 1. (A) Leaf area, (B) leaf number, (C) leaf dry weight, and (D) root dry weight of 'Ark-310' spinach transplants as affected by mulching (bare soil vs. black polyethylene mulch), and in-row plant spacing (15 cm vs. $25 \mathrm{~cm}$ ), Uvalde, Texas, 1995-96.
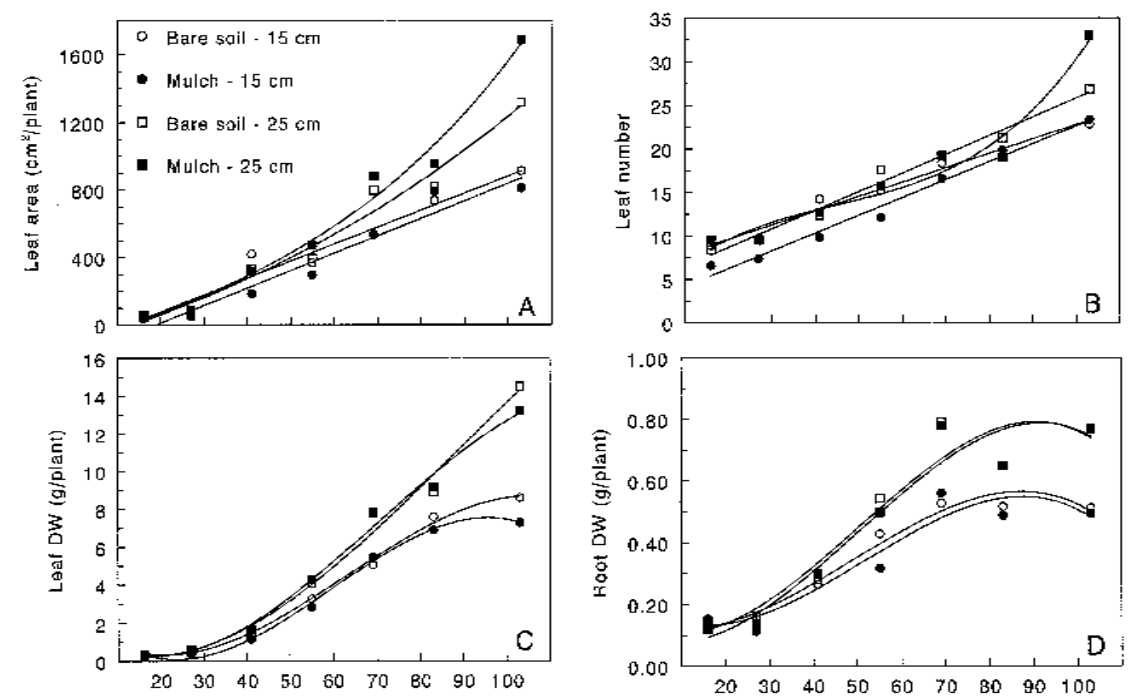

Time (d after transplanting)

Fig. 2. (A) Leaf area, (B) leaf number, (C) leaf dry weight, and (D) root dry weight of 'Ark-310' spinach transplants as affected by mulching (bare soil vs. black polyethylene mulch), and in-row plant spacing (15 cm vs. $25 \mathrm{~cm}$ ), Uvalde, Texas, 1997-98.
Leaf dry weight increased constantly with time (Fig. 1C). The slope $\left(b_{1}\right)$ was $42 \%$ greater for transplants grown on mulch $\left(1.36, r^{2}=\right.$ $0.97)$ than on bare soil $\left(0.96, r^{2}=0.98\right)$ at 0.25 -m spacing. Relative growth rates (dry weight basis) were not significantly different among treatments in either year, with a maximum and similar value of $0.037 \mathrm{~g} \cdot \mathrm{g}^{-1} \cdot \mathrm{day}^{-1}$ at 21 and 41 DAT in 1995 and 1997, respectively. In 1997-98, LDW increased constantly between 23 and 83 DAT, the increase was significantly greater for transplants grown at 25-cm spacings (Fig. 2C). Specific leaf area (SLA) was generally unaffected by planting systems in 1995 and 1997, except that plants spaced $25 \mathrm{~cm}$ on mulch had significantly higher values 49 DAT (147 vs. $81 \mathrm{~cm}^{2} \cdot \mathrm{g}^{-1}$ ) than did bare-soil plants spaced $25 \mathrm{~cm}$ in 1995 . Pooled across all treatments, SLA decreased from 162 to $66 \mathrm{~cm}^{2} \cdot \mathrm{g}^{-1}$ between 7 and 70 DAT. Young expanding leaves were thinner, but leaf thickness increased with plant maturity.

Root dry weight (RDW) in 1996 increased slowly between 7 and 42 DAT; thereafter, RDW of plants on mulch increased more rapidly than did that of plants on bare soil (Fig. 1D). At 70 DAT, RDW of plants spaced $25 \mathrm{~cm}$ on mulch averaged $1.7 \mathrm{~g}$ vs. $1 \mathrm{~g}$ for plants grown at $15 \mathrm{~cm}$ on mulch or bare soil (Fig. 1D). In 1997-98, root growth of transplants was greater at $25-\mathrm{cm}$ than at $15-\mathrm{cm}$ spacing, irrespective of mulch (Fig. 2D). In addition to root growth differences associated with plant spacing and mulching, spinach genotype may also influence root growth. Leskovar and Black (1994) noted that total RDW for ARK 88-354 and ACX 5044 genotypes established by direct seeding were 0.275 and $0.173 \mathrm{~g}$ per plant, respectively, $116 \mathrm{~d}$ after seeding.

Quality and yield. Plants on plastic mulch at $15-\mathrm{cm}$ spacing had $52 \%$ and $56 \%$ less soil on the leaves than did plants harvested from bare soil in 1996 and 1998, respectively (Fig. 3A). Averaged across both spacings, mulch decreased the amount of soil by $68 \%$ in 1998 . Fresh market spinach with a savoy leaf type is more prone to hold soil particles in leaf vein regions than is a processing smooth leaf type. During the 1998 season there were 25 rainfall events, four of them delivering $50 \mathrm{~mm}$ just prior to harvesting. One of the advantages of plastic mulch was to provide a cleaner product, since soil splashing to the leaves was minimized. Soil accumulation on the leaves because of wind, splashing, and/or harvesting can be further reduced by increasing plant population, as noted in the first experiment.

In 1996, yields were $42 \%$ higher at the closer plant spacing (Fig. 3B). Mulch increased yields by $20 \%$, a response that was independent of plant spacing (Fig. 3B). However, yields did not respond to either plant population or plastic mulch in 1998. In processed spinach, Bradley et al. (1975) reported a yield increase when in-row spacing decreased from 7.6 to $5.1 \mathrm{~cm}$. Osborne (1966) also noted a yield increase of processed spinach by spacing plants at $2.5 \mathrm{~cm}$ instead of $5.1 \mathrm{~cm}$. In our study, the maximum fresh market yield occurred when the ground area per plant was $375 \mathrm{~cm}^{2}$. In processing spinach established by direct 

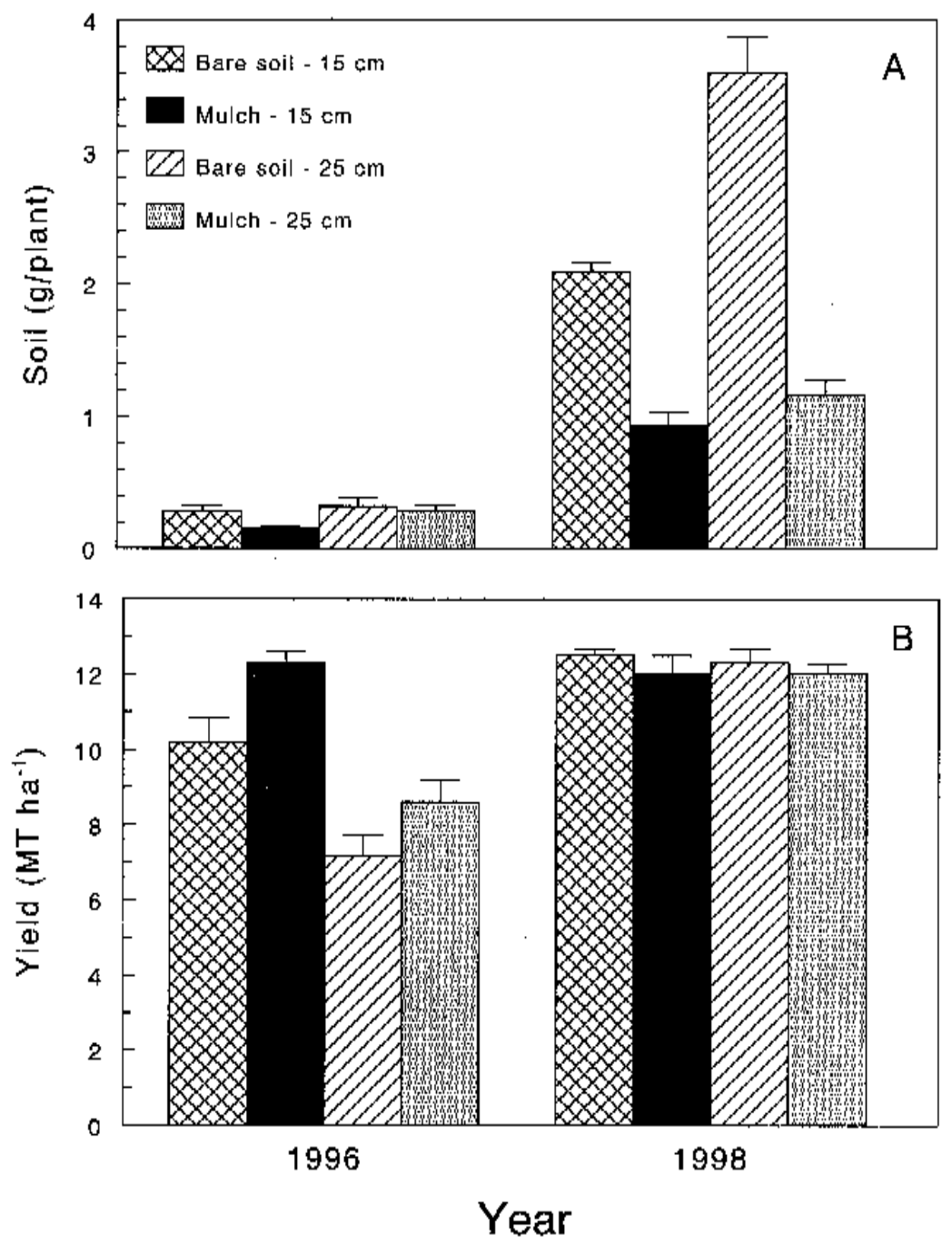

Fig. 3. Spinach (A) amount of soil content and (B) yield of 'Ark-310' spinach transplants as affected by mulching (bare soil vs. black polyethylene mulch), and in-row plant spacing $(15 \mathrm{~cm}$ vs. $25 \mathrm{~cm})$, Uvalde, Texas, 1996 and 1998. Vertical bars represent a mean $[n=40(\mathbf{A})$ and $n=4(\mathbf{B}) \pm$ SE] . seeding, maximum yield was reported at 65 $\mathrm{cm}^{2}$ ground area (Bradley et al., 1975).

In summary, the rates of increase in leaf area, and leaf and root dry weight were greater for plants spaced at $25 \mathrm{~cm}$, with vegetative growth being enhanced by mulch in both years. Leaf number, which increased constantly up to 25 leaves, and leaf thickness were generally less responsive to differences in planting systems. Mulch significantly reduced soil content after harvest, particularly under conditions of heavy rains in 1998. Mulch increased yield in one of two seasons, especially at $15-\mathrm{cm}$ spacing. Apparently, for a root-cut or loose leaf spinach product, yield efficiency and quality of 'Ark 310' spinach may be further improved by combining high plant density with efficient irrigation and fertilization programs under mulch and drip. However, the technical feasibility of producing a fresh root-cut spinach with those intensive production systems must be justified economically.

\section{Literature Cited}

Bradley, G.A., W.A. Sistrunk, E.C. Baker, and J.N Cash. 1975. Effect of plant spacing, nitrogen, and cultivar in spinach (Spinacea oleracea L.) yield and quality. J. Amer. Soc. Hort. Sci. 100:4548.

Ham, J.M., G.J. Kluitenberg, and W.J. Lamont. 1993. Optical properties of plastic mulches affect the field temperature regime. J. Amer. Soc. Hort. Sci. 118:188-193.

Lamont, W.J. 1993. Plastic mulches for the production of vegetable crops. HortTech. 3:35-39.

Leskovar, D.I. and M.C. Black. 1994. White rust infection and leaf chlorosis in relation to crop strategies in spinach. Env. Expt. Bot. 34:363370.

Osborne, H.F. 1966. Factors influencing the yield and quality of processed spinach. MS Thesis, Dept. of Horticulture, Univ. of Arkansas.

Zink, F.W. 1965. Growth and mineral absorption in spring spinach. Proc. Amer. Soc. Hort. Sci. 87:380-386. 